\title{
Environmental and emotional predictors of cognitive styles of air traffic controllers
}

\author{
Liubov Pomytkina ${ }^{1, *}$, Olena Ichanska ${ }^{1}$, Eduard Pomytkin ${ }^{2}$, and Vadim Yamnitsky ${ }^{3}$ \\ ${ }^{1}$ National Aviation University, 1, ave. Sviatoslav Huzar6 03058, Kyiv, Ukraine \\ ${ }^{2}$ Ivan Ziazun Institute of Pedagogical and Adult Education of the National Academy of Pedagogical \\ Sciences of Ukraine, 9, str. Maxim Berlinsky, 04060, Kyiv, Ukraine \\ ${ }^{3}$ Rivne State University of Humanities, 69/6, Str. Shkilnaб 33028 Rivne, Ukraine
}

\begin{abstract}
The article describes the theoretical and empirical study of cognitive styles of air traffic controllers as a guarantee of their professional success. The aim of the article was to present the results of the study, which were to establish the emotional predictors of cognitive styles of future air traffic controllers. The following methods were used for the study: "Gottschaldt's figures", "Comparison of similar drawings" by J. Kagan, "Free sorting of objects" by R. Gardner in the modification of V. Kolga, "Four-modal emotional questionnaire" by L.A. Rabinovych, "EmIn Emotional Intelligence Questionnaire" by D.V Lyusin, "Self-assessment of mental states" by G. Eisenk. The specifics of the manifestation of the following cognitive-stylistic parameters of air traffic controllers are analyzed: social field dependence-field independence, impulsivityreflexivity, analyticity-syntheticity. Based on the analysis of the results of the study, it was found that the vast majority of respondents have the following cognitive styles: field-independent $(77.7 \%)$, reflexive $(74.4 \%)$, and slightly less synthetic $(53.5 \%)$. Emotional intelligence at the intrapersonal and interpersonal levels of air traffic controllers is characterized by high rates in only half of the sample. Among emotions, almost half of the respondents are dominated by "joy" at a high level, "anger", "fear" at a low level and "sadness" at a medium level. It was also found that two thirds of air traffic controllers are dominated by low levels of anxiety and frustration. Regression analysis revealed the influence of emotional characteristics on cognitive styles of future air traffic controllers: "aggression" is a predictor of "field dependence", and "rigidity" and "joy" are predictors of analytical cognitive style.
\end{abstract}

\section{Introduction}

The modern world is characterized by dynamism and globalization of all spheres of life. One of the means of manifestation of these signs of modernity is the air transport industry, which develops itself due to the growth of transportation, increasing the popularity and accessibility of tourism and business contacts. Air traffic management is a risky activity that, due to automation and growth of the information load on the specialist, changed the

\footnotetext{
* Corresponding author: Lyubvit@bigmir.net
} 
structure of occupational risks, and, at the same time, intensified the issue of reliability of operator activities.

As known, among the professionally important skills both during training and during professional activities for air traffic controllers often refer to the following: speed and accuracy of decision-making, efficiency of making alternative decisions in conditions of time shortage, ability to analyze large amounts of information, flexibility of thinking, emotional stability. However, the professional activity of the air traffic controller provides not only a system of professional knowledge and skills, but also individual psychological characteristics, which are the basis of his psychological readiness and emotional resilience to activities in terms of a high risk and responsibility, readiness for timely and effective use of them in various extreme situations.

Therefore, the issue of interaction of emotional and cognitive characteristics, in particular, cognitive styles, remains relevant, especially in the context of professionally oriented training of air traffic controllers. The purpose of the article is to highlight the results of theoretical and empirical research, the establishment of emotional predictors of cognitive styles of future air traffic controllers.

\section{Main part}

Interest in the stylistic features of the activities of personality arose in the middle of our century due to the accumulation of data on the great individual differences that were observed in the study of perceptual processes. Such differences were defined as a manifestation of stylistic features of the personality in the direction known as the "New Look", due to which individual errors of perception have become a central point in the study of perceptual processes. As a result of active work of scientists, individual methods of information handling were identified, which were called "cognitive styles" (Brigham 2007 [17], Fuller, Kaplan 2004[20], Sadler-Smith 2004 [22], Golovina 2002 [2], Morozova 2002 [8], Kholodnaya 2004[13]). Summarizing the main definitions, we can say that cognitive styles are relatively stable cognitive strategies that are reflected in the individual perception and processing of information, as well as in its structuring, evaluation and control. These include: field dependence-field independence, smoothing-sharpening, tolerance to unrealistic experience, conceptual differentiation, reflexivity-impulsivity, cognitive complexity-simplicity, rigidity-flexibility, etc.

Today, studies of many scientists, both foreign (Chilton 2005 [18], Cools 2009 [19],) and domestic (Karpova E.V., Yablokova 2016 [7], Popova 2013 [9], Khokhlina 2013[14], Yashyn 2015[16]) show that the problem of cognitive styles not only remains relevant at the present stage of development of society, but also exacerbated as the cognitive sphere of human falls under the mass influence of Information Networks.

Modern research by scientists and practitioners indicates the need for a deeper study of cognitive styles of specialists, as well as the study of various interactions between individual psychological characteristics of specialists and cognitive styles. Thus, M.I. Popova notes the importance of defining cognitive styles during the training and selection of specialists in various fields of professional activity, as well as assessment and improvement of the effectiveness of professional activities of working specialists [9]. I.S. Morozova emphasizes that cognitive style characterizes the relationship of the personality with the surrounding reality and promotes adaptation [8].

The issue of cognitive-stylistic characteristics is considered by scientists and practitioners as promising for various areas of professional activity in aviation. The influence of individual cognitive processes on decision-making was studied by L.V. Pomytkina with a group of like-minded people $[1 ; 4 ; 6 ; 10]$. Researchers point out that an individual is able to make adequate decisions only if the cognitive-emotional sphere in a 
certain professional activity is developed. Instead, in the case of increased risks and fatigue, cognitive functions are reduced, which can lead to making wrong decisions, to loss of control over functional tasks [11]. The authors point out the importance of organizing psychological tests during the selection of flight crew of aviation workers [12].

In particular, O.M. Ichanska and M.O. Ivanyuk studied the problem of cognitive styles in the context of improving the quality of professional training of operators of special technical means of control in civil aviation. Researchers have identified field independent and reflective cognitive styles as those that promote more effective recognition by experts of prohibited for transportation items and substances and their parts by image on the X-ray television installation monitor [5]. O.V. Golovina considered the cognitive and stylistic determinants of personality confidence in solving sensory tasks, which allowed to create a method of studying psychological structures and trace their dynamics [2].

Cognitive-stylistic behavior in the field of air traffic control is considered in the research of N. Gordinya, who empirically revealed the influence of different types of cognitive style on the training of air traffic controllers, noting both constructive and destructive options [3].

Thus, scientists and practitioners point to the need to study the various interactions between cognitive styles and individual psychological characteristics of professionals, as well as to study their main determinants.

\section{Methods}

The basis of our research was to identify the most important emotional predictors that can influence the formation and development of certain cognitive styles of future aviation workers. The study involved 43 future air traffic controllers of the National Aviation University, with the field of study "Air Navigation".

To conduct the study, we selected a set of psychodiagnostic methods, which included two groups. The first group of three methods was selected to study the indicators of different cognitive styles of air traffic controllers: the method of "Gottschaldt's figures" was used to measure indicators of cognitive style "field dependence-field independence"; the method "Comparison of similar images" by J. Kagan was chosen to diagnose indicators of expression in our sample of cognitive style "impulsivity-reflexivity"; diagnosis of indicators of cognitive style "analytical-synthetic" was carried out using the method of "Free sorting of objects" by R. Gardner in the modification of V. Kolga. The second group of diagnostics from three methods was selected to study the indicators of different emotional characteristics of air traffic controllers: to determine the levels of basic emotions manifestation: anger, fear, joy, sadness, "Four-modal emotional questionnaire" by L.A. Rabinovich was used; diagnostics of different types of emotional intelligence and general emotional intelligence was carried out according to the method of "EmIn Emotional Intelligence Questionnaire" by D.V. Lusin; the method "Self-assessment of mental states" by G. Eisenk was used by us to measure anxiety, frustration, aggression, rigidity of air traffic controllers. Methods of mathematical statistics were used to process empirical data, namely: Pearson's criterion and multiple regression analysis.

\section{Results}

As a result of the empirical study, we obtained indicators that allow us to identify qualitative and quantitative manifestations of cognitive styles and emotional characteristics of future air traffic controllers (see Table 1). 
Table 1. Distribution of indicators of field dependence-field independence of air traffic controllers according to the method of K. Gottschaldt.

\begin{tabular}{|c|c|c|}
\hline Cognitive style & Number of persons & In percent \\
\hline Field dependence & 10 & 23.3 \\
\hline Field independence & 33 & 77.7 \\
\hline
\end{tabular}

The majority of respondents, namely $77.7 \%$, have a field dependent cognitive style: it is easier for these future air traffic controllers to overcome a complex context, distinguish details from a complex whole, reformulate and transform a given situation, distinguish parts from the whole. Field dependent cognitive style is inherent in $23.3 \%$ of respondents: these respondents perceive the situation as a whole, cannot divide into parts, identify contradictions in the task, demonstrate a global approach, they work better in a group, resolve conflict situations easier.

From the point of view of the specifics of the air traffic controller profession, for most of our respondents, namely for field independent workers, it is more comfortable to work with a lot of information that they read from devices and receive from other participants of the work process, they are characterized by flexibility of information processes, intelligence. Conversely, we can talk about the possible difficulties in the future professional activities of respondents with field dependent cognitive style, who slowly analyze the information obtained and make decisions, in conditions of lack of time and can get confused, make the wrong decision. Considering the level of responsibility of the air traffic controller, this style of perception and processing of information can be problematic for effective professional activity. Therefore, field independence is one of the most important cognitive characteristics for future air traffic controllers, which affects their success in professional training and further professional activity.

The obtained distribution of impulsivity-reflexivity is given in Table 2 .

Table 2. Distribution of indicators of impulsivity-reflexivity of air traffic controllers according to the method of V.E. Kagan.

\begin{tabular}{|c|c|c|}
\hline Cognitive style & Number of persons & In percent \\
\hline Impulsivity & 11 & 25.6 \\
\hline Reflexivity & 32 & 74.4 \\
\hline
\end{tabular}

The majority of respondents $(74.4 \%)$ have a reflexive cognitive style, i.e. they primarily perceive and analyze the information received, try to rely on their own experience, analyzing the problem situation and making decisions, thus avoiding many mistakes, but an important factor is the time spent on decision making. Impulsive cognitive style prevails in $25.6 \%$ of respondents, which is characterized by speed of decision-making, but quite often by missing the assessment of the situation, the analysis is superficial and not systematic, which leads to an increase in the number of mistakes. Therefore, such specialists can work effectively only when there is a consistent plan, step-by-step preliminary analysis, which requires time, and the professional activity of air traffic controllers is extremely dynamic, requires quick decision-making, ability to accurately perceive and analyze information, speed of thinking.

The distribution of analyticity-syntheticity indicators of air traffic controllers is given in Table 3.

Table 3. Distribution of analyticity-syntheticity indicators of air traffic controllers according to the method of R. Gardner in the modification of V. Kolga.

\begin{tabular}{|c|c|c|}
\hline Cognitive style & Number of persons & In percent \\
\hline Analytical & 14 & 32.5 \\
\hline Mixed & 6 & 14.0 \\
\hline Synthetical & 23 & 53.5 \\
\hline
\end{tabular}


Synthetic cognitive style predominates in our sample: in $53.5 \%$ of respondents cognitive style is based on the ability to operate with more generalized conceptual structures, their wide range of equivalence contributes to the formation of cognitive interests, so they are ready to work effectively in situations of uncertainty, can analyze the situation more broadly, taking into account all its aspects. One third of the respondents have an analytical cognitive style, i.e. they focus on the signs of differences in the assessment of objects, have a narrow range of equivalence, tend to logical and careful problem-solving strategies, focus on details. Despite their competence in their field, in situations of uncertainty it is difficult for them to quickly and accurately assess the situation that has arisen.

Also, $14.0 \%$ of respondents have a mixed type of analyticity-syntheticity equivalence range: these respondents properly assess the situation holistically, but not forgetting the details that are included in it, combining the above 3 cognitive styles. This cognitive style is inherent in individuals who are able to adequately and quickly assess and group the information received on certain similar signs, which will help in future professional activities when processing large amounts of information, following algorithms, and in case of emergencies will allow to clearly and holistically assess the situation.

In our study, we talk about the role of emotional characteristics in the functioning of cognitive styles of future air traffic controllers. Therefore, it was necessary to further determine the emotional characteristics of the respondents (see Figure 1).

\begin{tabular}{|c|c|c|c|c|c|}
\hline \multicolumn{6}{|l|}{$100 \%$} \\
\hline \multicolumn{6}{|l|}{$50 \%$} \\
\hline $0 \%$ & very low & low & middle & high & very high \\
\hline$\square \mathrm{GEI}$ & 2,8 & 8,7 & 20 & 54,3 & 14,3 \\
\hline EM & 5,8 & 2,8 & 37,3 & 37,3 & 2,8 \\
\hline UE & 5,8 & 37,3 & 28,5 & 42,9 & 2,8 \\
\hline a laEl & 2,8 & 5,8 & 37,3 & 51,3 & 2,8 \\
\hline
\end{tabular}

Fig. 1. Distribution of percentages of characteristics of emotional intelligence of air traffic controllers according to the method of D.V. Lusin.

Notes: IeEI - interpersonal emotional intelligence; IaEI - intrapersonal emotional intelligence; UE - understanding of emotions; EM - emotion management; GEI-general emotional intelligence.

The majority of the sample - $42.9 \%$ of respondents - have high indicators of understanding emotions (UE), which indicates their ability to understand the relationship between their own emotions, thoughts and behavior, to realize the value of emotions, the causes of emotional experiences. Also, in most respondents, emotion management (EM) is expressed at medium and high levels (37.3\% of the sample), which indicates their ability to control emotions, the ability to regulate the manifestations and intensity of negative emotions, the ability to stimulate the expression of positive emotional experiences. 
Interpersonal emotional intelligence (IeEI) in most respondents is expressed at a high level $-51.3 \%$, this indicator characterizes the ability to understand and manage the emotions of others, which provides mutual understanding with the environment, the effectiveness of interaction in conditions of training for professional activities. Intrapersonal emotional intelligence (IaEI) in most of our respondents is at a high level $51.3 \%$, which indicates their ability to understand their own experiences, as well as willingness to effectively control their own behavior.

Half $(54.2 \%)$ of respondents have a high general level of emotional intelligence (EI): they have good control over the manifestations of their own emotions, are able to understand the emotional experiences of others, do not tend to use destructive, antisocial strategies, easily adapt to others, maintaining their own boundaries, effectively establish interpersonal and business relationships. Only $14.3 \%$ of the sample have a very high level of emotional intelligence, and therefore, a strong ability to understand their own emotions and the emotions of others, to manage the emotional sphere, which leads to greater adaptability and efficiency in communication and allows them to make decisions based on reflection and understanding of emotions, which are a differentiated assessment of events that have personality significance, the effectiveness of emotional self-regulation.

Presented points allow these respondents to effectively and quickly enter into different types of relationships with different types of respondents, ensuring their emotional competence. Also, $20 \%$ have average indicators of general emotional intelligence, which is manifested in the ability to detect it effectively in typical situations, but unpreparedness for non-standard emotional situations. And, respectively, $8.7 \%$ and $2.8 \%$ have low and very low levels of general emotional intelligence, which is manifested in the inability to understand the full range of their own emotions and the emotions of others, inability to control the manifestations of their own emotions and emotions of others, and the tendency to choose manipulative, antisocial and aggressive actions as basic patterns of behavior (see Figure 2).

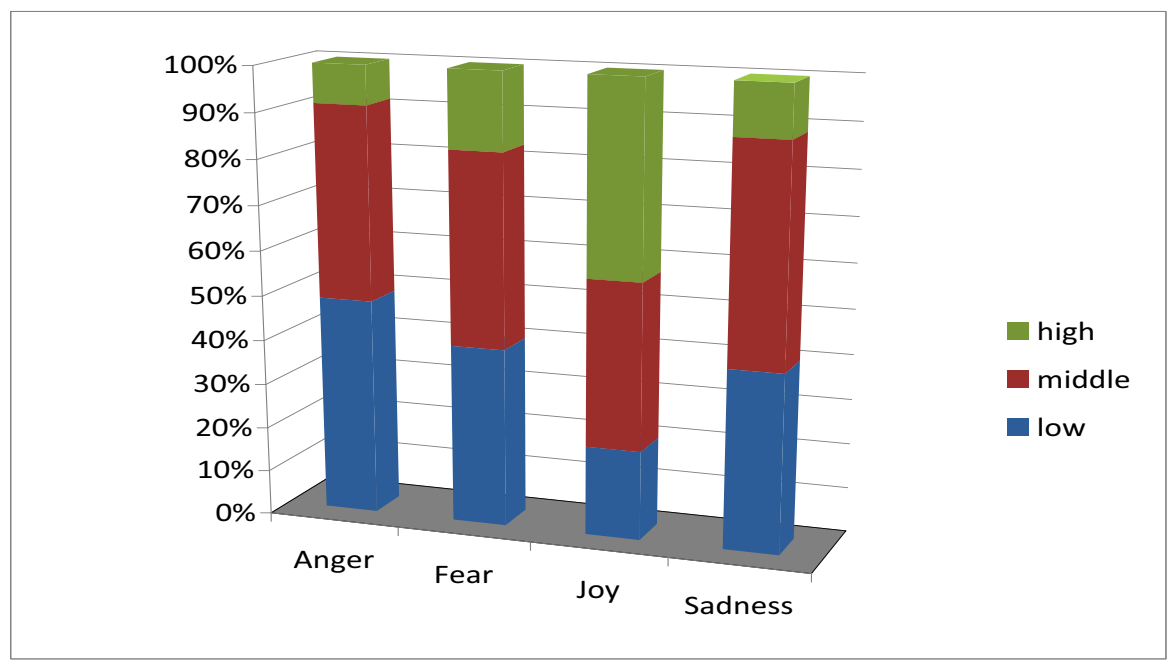

Fig. 2. Distribution of percentages of manifestation levels of basic emotions of air traffic controllers according to the method of L.A. Rabinovich.

The emotion of "anger" is dominated by low (48.5\%) and medium (42.9\%) level, i.e. in most respondents the negatively colored affect is manifested not brightly, but only in certain types of situations and directed against injustice and accompanied by a desire to eliminate it. Fear as anxiety caused by receiving direct or indirect information about a real 
or perceived threat, found in our respondents at a low level - in most respondents - $48.5 \%$, who are not prone to expect failure while doing actions due to the situation.

The emotion of joy dominates at a high level in $42.9 \%$ of respondents, this emotion contributes to the sensitivity of respondents to every life situation, to every impression of life, both physical and moral, which ensures the integrity of life experience in achieving goals, meeting needs, solving tasks and is more often associated with future employment.

The motion of sadness dominates at the average level in $48.6 \%$ of respondents who are situationally prone to experience it in the absence of satisfaction, loss, frustration, also manifested in inhibition of motility, narrowing of blood vessels, slowing their not only physical but also mental activity, which can negatively affect not only the general mood, but also the performance of current tasks. The emotion of sadness is more focused on the past and present of air traffic controllers (see Figure 3).

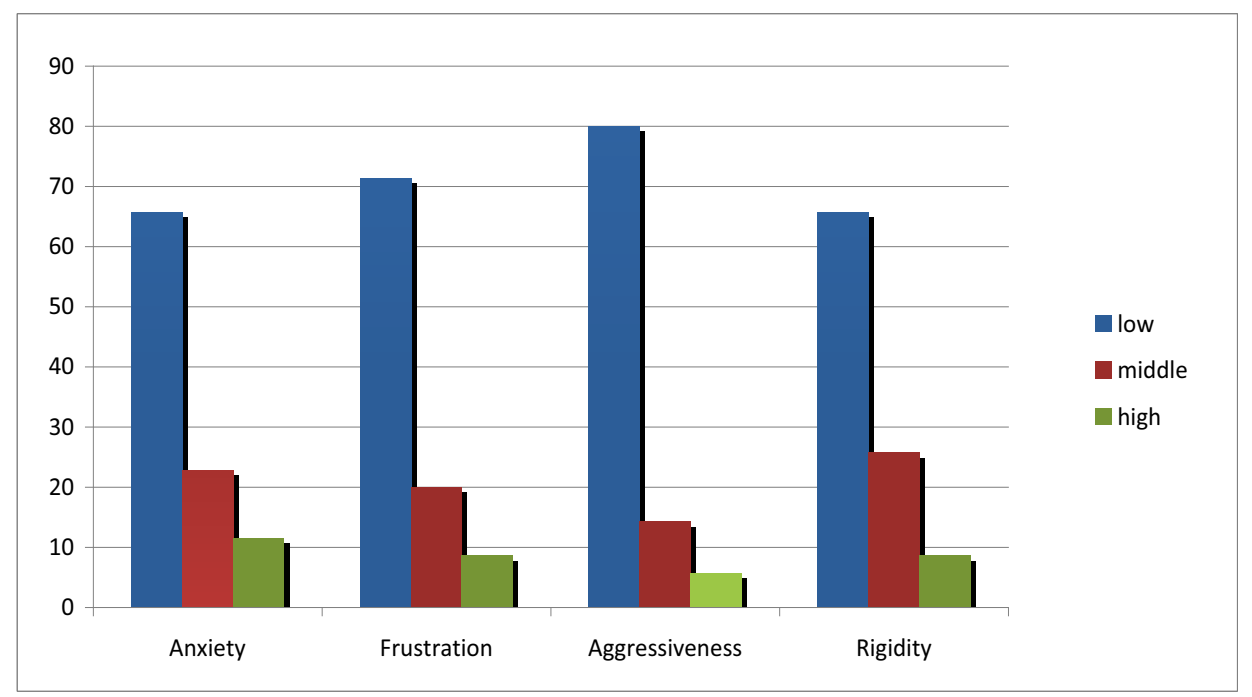

Fig. 3. Distribution of percentages of levels of emotional states of air traffic controllers according to the method of G. Eisenk.

It was found that the vast majority of the sample (65.7\%) have low anxiety, i.e. more typical for them are calmness, balance, the ability to bring things to a logical conclusion, calmly responding to changes in the algorithm. The average level of anxiety is observed in $22.8 \%$ of respondents, they are characterized by a tendency to detect it in unusual situations. High levels of anxiety are present in $11.5 \%$ of subjects, who are characterized by tension, anxiety, premonition of danger and failure, regardless of the situation.

A low level of frustration was found in $71.4 \%$ of respondents, who have a quite high self-esteem, they are resistant to failure, do not stop on achieved, are able to act under the influence of current emotions and circumstances. A high level of frustration is present in $8.6 \%$ of the sample, which is characterized by low self-esteem, in difficult situations tend to run away, avoid failure, which is an obstacle to the effective work of the air traffic controller. $80 \%$ of respondents are not aggressive, they are restrained and calm, and $14.3 \%$ of respondents have an average level of aggression, they are characterized by a tendency to change mood, willingness to situational desire to vent emotions, but also the ability to selfcontrol their irritability.

Also, $65.7 \%$ of respondents do not have rigidity, they easily switch from one case to another, ready for change. High level of rigidity only in $8.6 \%$ of respondents who find it 
difficult and long to adapt to new conditions, conservative, do not want to change anything, abrupt changes cause them stress.

To process the results of the empirical study, a multiple regression analysis was performed to identify variables that are determinants of cognitive styles in future air traffic controllers with a preliminary determination of the type of data distribution using the Kolmagorov-Smirnov criterion and the corresponding to it link by Pearson's criterion (see Table 4).

Table 4. Correlations of indicators of analytical cognitive style and emotional characteristics of respondents.

\begin{tabular}{|c|c|c|c|c|c|}
\hline $\begin{array}{c}\text { Cognitive } \\
\text { style } \\
\text { "Analytical" }\end{array}$ & $\begin{array}{c}\text { According to Pearson's } \\
\text { criterion }\end{array}$ & Rigidity & Anxiety & Joy & Frustration \\
\cline { 2 - 6 } & Significance indicator & $0.728^{* *}$ & $0.708^{*}$ & $0 .-643^{* *}$ & $0.670^{*}$ \\
\cline { 2 - 6 } & Criterion indicator & 0.011 & 0.022 & 0.033 & 0.024 \\
\hline
\end{tabular}

There is a direct link between analytical cognitive style and rigidity: for the respondents with analytical type studying activities are more difficult, they tend to evaluate all the little things and details, follow a specific algorithm, and react emotionally to sudden changes and situations of uncertainty. This connection can negatively affect the ability to work by profession, as in extreme situations it will be difficult for them to quickly assess the overall picture and make an effective decision. There is a direct link between analytical cognitive style and anxiety: respondents with an analytical type tend to perform well in social requirements and are strongly focused on social acceptance, and therefore tend to show anxiety, worrying when it is impossible to confirm the expectations of others. There is also another connection, namely frustration and analytical cognitive style: analysts are characterized by avoidance of failures, which provokes them frequent and intense experience of frustration, which is the result of their analytical activities.

There was an inverse relationship between the emotion of "joy" and analytical cognitive style: the more our respondents tend to analyze, detailing, separate components from the whole, the lower the level of joy is, i.e. a positive attitude to life, this can be explained by obsession with certain components of different situations, and such detailing has a negative effect on a positive attitude, so the smaller the indicators on the scale of "joy" will be.

Indicators of correlation of field dependent cognitive style and emotional characteristics of air traffic controllers are given in Table 5.

Table 5. Correlations of indicators of field dependent cognitive style and emotional characteristics of air traffic controllers.

\begin{tabular}{|c|c|c|}
\hline \multirow{2}{*}{$\begin{array}{c}\text { Cognitive style } \\
\text { "field dependent" }\end{array}$} & By Pearson's criterion & Agression \\
\cline { 2 - 3 } & Significance indicator & $-0.741^{* *}$ \\
\cline { 2 - 3 } & Criterion indicator & 0.035 \\
\hline
\end{tabular}

There is an inverse relationship between field dependent cognitive style and aggression. Field dependent respondents are more passive, they slowly analyze and evaluate the information obtained, cautiously hypothesize and make decisions, they tend to listen to others, not fighting for their own point of view, openly not defending their own interests, aggression is not too typical for them.

The next stage of our work was to conduct a regression analysis, based on the results of which we can draw conclusions about the two cognitive styles of future air traffic controllers. Dependent variable "field dependent cognitive style": the coefficient of multiple determination shows that $76 \%$ of field independence is determined by such an independent variable as: aggression. The formula of the regression model of this dependent variable has the following form: 
Field dependent cognitive style $=2,000-0,050$ (Aggression)

Field dependent respondents are not ready to express their emotions even when they are not satisfied with something, they tend to remain silent and accept the situation. Due to the emotional reaction, they remain loyal to the environment, they are more empathetic and non-conflicting, but are unable to assess and respond to their own irritability, which can be a destructive factor for the responsible work of the air traffic controller.

Dependent variable "analytical cognitive style": the coefficient of multiple determination shows that the analytical cognitive style is determined by such independent variables as: rigidity and joy. The formula of the regression model of this dependent variable has the following form:

Analytical cognitive style $=9,035+0,198$ (rigidity) - 0, 084 (joy)

Analytical cognitive style of air traffic controllers is determined by the tendency to rigidity, their unwillingness to switch from those emotions associated with current situations. The focus on details in the cognitive analysis of the situation of these respondents is associated with a focus on separate emotions, limited ability to adequately respond emotionally to sudden changes and situations of uncertainty. Also, the tendency to analytical cognitive style of air traffic controllers increases with decreasing intensity of emotion "joy": in this case, the optimal will be the average indicators on the scale of "joy", which will allow respondents to adequately assess the situation and respond to it, because in the case of high indicators of this emotion we can talk about too infantile attitude to work processes.

\section{Discussion}

The question of the prospects of the study of cognitive styles in aviation specialists is not in doubt, which is actively represented in the works of foreign and domestic scientists and researchers. At the same time, the issue of determining the constructiveness and destructiveness of certain cognitive styles in the professional activities of air traffic controllers remains debatable. In particular, it concerns the analytical style, which, from our point of view, has certain limitations in comparison with synthetic and mixed styles, and also has such predictors as: rigidity, reduction of intensity of experience of emotion "joy". The question of the interaction of cognitive styles and other indicators, the dynamics of cognitive-stylistic characteristics in terms of professionally-oriented training is also studied insufficiently. Therefore, the problem of studying other factors not involved by us and their influences on cognitive styles of air traffic controllers remains relevant.

\section{Conclusion}

Field dependence can be assessed as a negative cognitive and stylistic feature for the future air traffic controller, it is characterized by a global perception of reality, the dependence of decisions on external factors, the opinions of others. In addition, air traffic controllers with such a cognitive style are unable to detect, assess and adequately respond to their own irritability, which can be a destructive factor for the emotionally professional activities of the air traffic controller. Cognitive style "analytical" is determined by the following variables: "rigidity" and "joy". Air traffic controllers with an analytical cognitive style tend to be rigid, obsessed with their own emotional experiences, using analytical skills as a tool for repeated playback of emotionally traumatic situations. Also, such respondents have a lower overall level of joy, i.e. a positive attitude to life.

The results of the study allow us to say that some respondents are dominated by cognitive styles, which complicate the process of training for future professional activities. 
We also found significant indicators of frustration, anxiety and aggression in some respondents. Therefore, the prospects of our work will be to create and test a model of psychological training aimed at the development of cognitive abilities: analytical-synthetic style of thinking, flexibility of thinking, figurative thinking, concentration and stability of attention. We envisage a separate block of training to focus on the development of the emotional sphere, in particular, the emotional intelligence of future air traffic controllers, skills of recognizing aggression and mastering constructive methods of overcoming it, increasing tolerance to frustration, reducing situational anxiety, developing self-regulation skills, developing emotional differentiation skills.

Our further research may be to identify other determinants of the formation of cognitive styles of future air traffic controllers in the context of educational and professional training.

\section{References}

1. O.V. Hirchuk, E.O. Pomytkin, L.V. Pomytkina, Safety in Aviation And Space Technologies (NAU, Kyiv, 2018)

2. E.V. Holovyna, Metodi yssledovanyia psykholohycheskykh struktur y ykh dynamyky (YP RAN, M, 2002)

3. N.D. Hordinia, Molodoi uchenii 5(52), 634-638 (2013)

4. A. Gudmanian, L. Pomytkina, O. Kovtun, S. Yahodzinskyi, E3S Web of Conferences 164, 10021 (2020) https://doi.org/10.1051/e3sconf/202016410021

5. O.M. Ichanska, M.O. Ivaniuk, Aviatsiina ta ekstremalna psykholohiia $u$ konteksti tekhnolohichnykh dosiahnen: zbirnyk naukovykh prats (Ahrar Media Hrup, K., 2017)

6. V.M. Kazak, D.O. Shevchuk, N.A. Tymoshenko, L.V. Pomytkina, IEEE $4^{\text {th }}$ International Conference "Methods and Systems of Navigation and Motion Control (MSNMC)” (Kiev, Ukraine, 2016) DOI: https://doi.org/10.1109/msnms.2016.7783150

7. E.V. Karpova, A.V. Yablokova, Yaroslavskyi pedahohycheskyi vestnyk 6, 220-226 (2016)

8. Y.S. Morozova, Sybyrskaia psykholohyia sehodnia: sb. nauch. tr. 1, 30-36 (2002)

9. M.I. Popova, Psykholohichni perspektyvy 22, 209-217 (2013) DOI: https://doi.org/10.32626/2227-6246.2019- 46.308-326

10. L.V. Pomytkina, XIV Mizhnarodna naukovo-tekhnichna konferentsiia "AVIA-2019" 37.10-37.11 (2019)

11. L.V. Pomytkina, Indyvidualnist u psykholohichnykh vymirakh spilnot ta profesii $v$ umovakh merezhevoho suspilstva: Monohrafiia kolektyvna (TOV «Alfa-PIK», K., 2019)

12. L.V. Pomytkina, Aviatsiina ta ekstremalna psykholohiia u konteksti tekhnolohichnykh dosiahnen: zbirnyk naukovykh prats (TOV «Alfa-PIK», K., 2019)

13. M.A. Kholodnaia, Kohnytyvnie styly: o pryrode yndyvydualnoho uma (Pyter, SPb, 2004)

14. O.P. Khokhlina, Problemy ekstremalnoi ta kryzovoi psykholohii Kharkiv 14(II), 391399 (2013)

15. Y.P. Shkuratova, Stylevoi podkhod k yssledovanyiu lychnosty: problemi y perspektyv: Yndyvydualnie y stylevie osobennosty lychnosty (YuRHY, Rostov-na-Donu, 2002)

16. A.A. Yashyn, Psykholohyia y Psykhotekhnyka 11, 1146-1157 (2015)

17. K.H. Brigham, J.O. De Castro, D.A. Shepherd, Entrepreneurship Theory and Practice 31, 29-51 (2007) 
18. M.A. Chilton, B.C. Hardgrave, D.J. Armstrong, Journal of Management Information Systems 22(2), 193-226 (2005)

19. E. Cools, Vlerick Leuven Gent Working Paper Series 2, 2-47 (2009)

20. L.R. Fuller, S.E. Kaplan, Behavioral Research in Accounting 16, 131-143 (2004)

21. E. Lofstrom, Studies for the learning society 1, 49-61 (2008)

22. E. Sadler-Smith, Organization Studies 2, 155-181 (2004) 